\title{
Outcomes of total arch replacement with stepwise distal anastomosis technique and modified perfusion strategy
}

\author{
Shigefumi Matsuyama, MD, ${ }^{\mathrm{a}}$ Minoru Tabata, MD, MPH, ${ }^{\mathrm{a}}$ Tomoki Shimokawa, MD, ${ }^{\mathrm{b}}$ \\ Akihito Matsushita, MD, ${ }^{\mathrm{a}}$ Toshihiro Fukui, MD, ${ }^{\mathrm{a}}$ and Shuichiro Takanashi, $\mathrm{MD}^{\mathrm{a}}$
}

\begin{abstract}
Objective: Total arch replacement has been reported to present high morbidity and mortality. We have introduced a stepwise distal anastomosis technique and modified perfusion strategy, including selective antegrade cerebral perfusion, moderate hypothermia, and separate lower-body perfusion, to minimize organ ischemia and secondary morbidities. We report the operative outcomes of total arch replacement with our modified perfusion strategy.
\end{abstract}

\begin{abstract}
Methods: Between August 2006 and December 2008, 119 patients underwent total arch replacement with the current perfusion strategy. Of these patients, $56(47 \%)$ underwent emergency operation for acute type A aortic dissection $(n=48)$ or ruptured thoracic aneurysm $(n=8)$. The mean age of patients was 68 years, and the mean follow-up period was 25 months. We analyzed operative mortality, morbidity, and 4-year survival of this patient group.

Results: The mean operation, cardiopulmonary bypass, and circulatory arrest times were 313,183 , and 47 minutes, respectively. Operative mortality was $3.4 \%$. Operative mortality of elective cases was $1.6 \%$. The incidences of permanent neurologic deficit, paraparesis, and renal insufficiency were 5.0\%, $1.7 \%$, and $7.6 \%$, respectively. Actuarial 4-year survival was $86.5 \%$.
\end{abstract}

Conclusions: Total arch replacement with our modified perfusion strategy has demonstrated low operative mortality and morbidity. (J Thorac Cardiovasc Surg 2012;143:1377-81)

Total arch replacement (TAR) has been reported to demonstrate high morbidity and mortality. Various operative techniques and cerebral protection strategies have been presented to improve the operative outcomes of TAR. The stepwise distal anastomosis technique was introduced as an effective method to control bleeding from the distal anastomosis. ${ }^{1}$ In this technique, an invaginated tube graft is inserted into the distal aorta, the graft is sewn on the aorta with running sutures, the end of the inserted graft is pulled out, and the graft is anastomosed in a 4-branched graft. ${ }^{1}$ We have used this technique as a routine in TAR. One of its drawbacks is a prolonged hypothermic circulatory arrest (HCA) time because of an additional anastomosis. ${ }^{1}$ To shorten HCA time and prevent organ ischemia, we introduced separate lower-body perfusion and antegrade selective cerebral perfusion (SCP) in 2006. We report the outcomes of a recent series of TAR using this stepwise distal anastomosis technique and modified perfusion strategy. We

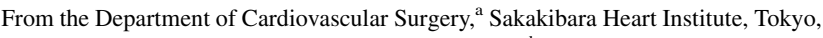
Japan; and Department of Cardiovascular Surgery, ${ }^{\mathrm{b}}$ Teikyo University Hospital, Tokyo, Japan.

Disclosures: Authors have nothing to disclose with regard to commercial support. Received for publication March 14, 2011; revisions received June 10, 2011; accepted for publication July 13, 2011; available ahead of print Aug 8, 2011.

Address for reprints: Minoru Tabata, MD, MPH, Department of Cardiovascular

Surgery, Sakakibara Heart Institute, 3-16-1 Asahicho, Fuchu, Tokyo, 183-0003,

Japan (E-mail: mtabata@post.harvard.edu).

$0022-5223 / \$ 36.00$

Copyright (c) 2012 by The American Association for Thoracic Surgery

doi:10.1016/j.jtcvs.2011.07.016
}

also compared these outcomes with those of our previous series using the arch first technique with retrograde cerebral perfusion (RCP).

\section{PATIENTS AND METHODS}

This study was approved by the institutional review board, and a waiver of informed consent was obtained. Between August 2006 and December 2008, 119 patients underwent TAR at Sakakibara Heart Institute. Fiftysix patients $(47 \%)$ had an emergency operation. Of these patients, 48 had acute type $\mathrm{A}$ aortic dissection and 8 had ruptured thoracic aortic aneurysm. Among 63 patients undergoing elective surgery, 56 had true aneurysm and 7 had chronic dissected aneurysm. Our indication of TAR included aneurysm of the aortic arch and acute aortic dissection with distal arch dilation or entry located in the distal aortic arch. The mean age of patients was $68 \pm 12$ years, and $25(21 \%)$ were women. Fifteen patients $(12.5 \%)$ had a reoperative sternotomy after previous cardiac surgery. The other patients' characteristics are shown in Table 1. We performed concomitant procedures in 37 patients: coronary artery bypass grafting in 30 , aortic valve replacement in 4 (including 2 patients undergoing concomitant coronary artery bypass grafting and aortic valve replacement), Bentall operation in 3, and aortic reimplantation in 2 . The mean follow-up period was $25 \pm 15$ months.

Between January 2004 and August 2006, 67 patients underwent TAR using the arch first technique with RCP. Preoperative characteristics and operative variables are shown in Table 1.

Perioperative data were collected from patients' medical records. Transient neurologic deficit was defined as a central neurologic deficit that has resolved within 72 hours, and permanent neurologic deficit was defined as a central neurologic deficit persisting for more than 72 hours. All permanent neurologic deficits were confirmed by computed tomography or magnetic resonance imaging. Postoperative renal insufficiency was defined as serum creatinine more than $2.0 \mathrm{mg} / \mathrm{dL}, 2$ times more than the most recent preoperative creatinine level, or new requirement for dialysis postoperatively. 


\section{Abbreviations and Acronyms \\ $\mathrm{HCA}=$ hypothermic circulatory arrest \\ $\mathrm{RCP}=$ retrograde cerebral perfusion \\ $\mathrm{SCP}=$ selective cerebral perfusion \\ $\mathrm{TAR}=$ total arch replacement}

Respiratory failure was defined as a requirement for mechanical ventilation for more than 48 hours postoperatively. Operative mortality was defined as any death within 30 days after surgery or before discharge.

Summary statistics were constructed using frequencies and proportions for categoric data, and mean \pm standard deviation or median if appropriate for continuous variables. Univariate analyses were carried out using the $t$ test or Mann-Whitney $U$ test for continuous variables and the chi-square or Fisher exact test for categoric variables. Survival was estimated using the Kaplan-Meier method.

\section{Surgical Procedure}

All operations were performed via a median sternotomy. In aortic dissection cases, the initial arterial cannula was placed in the femoral artery in most cases. The axillary artery or left ventricular apex was cannulated if the femoral artery was unavailable. In true aneurysm, the initial arterial cannula was placed in the ascending aorta.

All patients were cooled to $25^{\circ} \mathrm{C}$ for circulatory arrest. We established SCP during circulatory arrest by inserting $12 \mathrm{~F}$ balloon catheters into 3 cerebral branches and snaring them to prevent balloon dislodgement. The balloon catheters were set inside each branch of the 4-branched vascular graft before circulatory arrest. A separate circuit was used for SCP. The flow rate of SCP was kept at 15 to $20 \mathrm{~mL} / \mathrm{kg} / \mathrm{min}$ to maintain the perfusion pressure at more than $50 \mathrm{~mm} \mathrm{Hg}$, and the temperature of SCP was kept at $25^{\circ} \mathrm{C}$ after starting to rewarm the body. Intermittent cold blood cardioplegia was administered both antegradely and retrogradely every 20 to 30 minutes. To avoid recurrent laryngeal nerve injury, we divided the greater curvature of the distal arch and transected the aorta distally to the nerve. A folded elephant trunk graft was inserted into the distal aorta and anastomosed to the aorta with running sutures. The elephant trunk graft was then unfolded to pull up the proximal end of the graft. Hemostasis of the distal anastomosis was confirmed by pumping blood through a cannula in the femoral artery and clamping the proximal end of the graft. Then, separate lower-body perfusion was resumed through a femoral arterial cannula with the balloon occlusion of the elephant trunk. If the femoral artery was unavailable or the descending or abdominal aorta was atheromatous, lower-body perfusion was established through a balloon catheter placed in the elephant trunk. The patient was warmed to $30^{\circ} \mathrm{C}$ after establishing lower-body perfusion in addition to SCP. A 4-branched vascular graft was anastomosed to the elephant trunk graft (Figure 1), and cerebral branches were separately reconstructed. The 4-branched graft and elephant trunk graft always have the same size because we divide 1 graft into 2 pieces. Total body perfusion was resumed through the fourth branch of the prosthesis after SCP was discontinued, and the patient was warmed to $35^{\circ} \mathrm{C}$. Subsequently, hemostasis of graft-to-graft and 3 cerebral anastomoses was confirmed. The proximal anastomosis was performed during rewarming. The sequence of anastomoses is shown in Figure 2. The surgical techniques of previous series using the arch first technique and RCP have been described. ${ }^{2}$

\section{RESULTS}

The operative variables and outcomes are shown in Table 2 . The mean operation, cardiopulmonary bypass, SCP, and lower-body HCA times (including all concomitant
TABLE 1. Preoperative characteristics

\begin{tabular}{lccc}
\hline \multicolumn{1}{c}{ Variables } & $\begin{array}{c}\text { Current } \\
\text { technique } \\
(\mathbf{n = 1 1 9 )}\end{array}$ & $\begin{array}{c}\text { Arch first } \\
\text { technique } \\
(\mathbf{n}=\mathbf{6 7})\end{array}$ & $\begin{array}{c}\boldsymbol{P} \\
\text { value }\end{array}$ \\
\hline Age (y) & $68 \pm 12$ & $68 \pm 11$ & .779 \\
Male & $94(79 \%)$ & $50(74.6 \%)$ & .494 \\
Emergency operation & $56(47.1 \%)$ & $43(64.2 \%)$ & .025 \\
True aortic aneurysm & $64(53.8 \%)$ & $34(50.7 \%)$ & .691 \\
Acute aortic dissection & $48(38.7 \%)$ & $31(46.3 \%)$ & .432 \\
Chronic aortic dissection & $7(5.9 \%)$ & $2(3.0 \%)$ & .308 \\
Concomitant procedures & $37(31.1 \%)$ & $18(26.9 \%)$ & .470 \\
Coronary artery bypass grafting & $30(25.2 \%)$ & $14(20.9 \%)$ & .506 \\
Aortic root replacement & $5(4.2 \%)$ & $4(6.0 \%)$ & .416 \\
Aortic valve replacement & $4(3.4 \%)$ & $0(0 \%)$ & .104 \\
Hypertension & $99(83.2 \%)$ & $51(76.1 \%)$ & .241 \\
History of cerebrovascular & $18(15.1 \%)$ & $8(11.9 \%)$ & .548 \\
$\quad$ disease & & & \\
Previous cardiac operation & $15(12.6 \%)$ & $2(3.0 \%)$ & .029 \\
Moderate or severe chronic & $9(7.6 \%)$ & $2(3.0 \%)$ & .204 \\
$\quad$ obstructive pulmonary disease & & & \\
Hemodialysis & $3(2.5 \%)$ & $1(1.5 \%)$ & .643 \\
\hline
\end{tabular}

procedures) were $313 \pm 67,183 \pm 41,89 \pm 18$, and $47 \pm$ 15 minutes, respectively. Compared with our previous series, the times were significantly shorter. The operative mortalities were $3.4 \%(4 / 119)$ in all cases, $1.6 \%(1 / 63)$ in elective cases, $5.4 \%(3 / 56)$ in emergency cases, and $4.2 \%$ $(2 / 48)$ in acute aortic dissection cases. The causes of

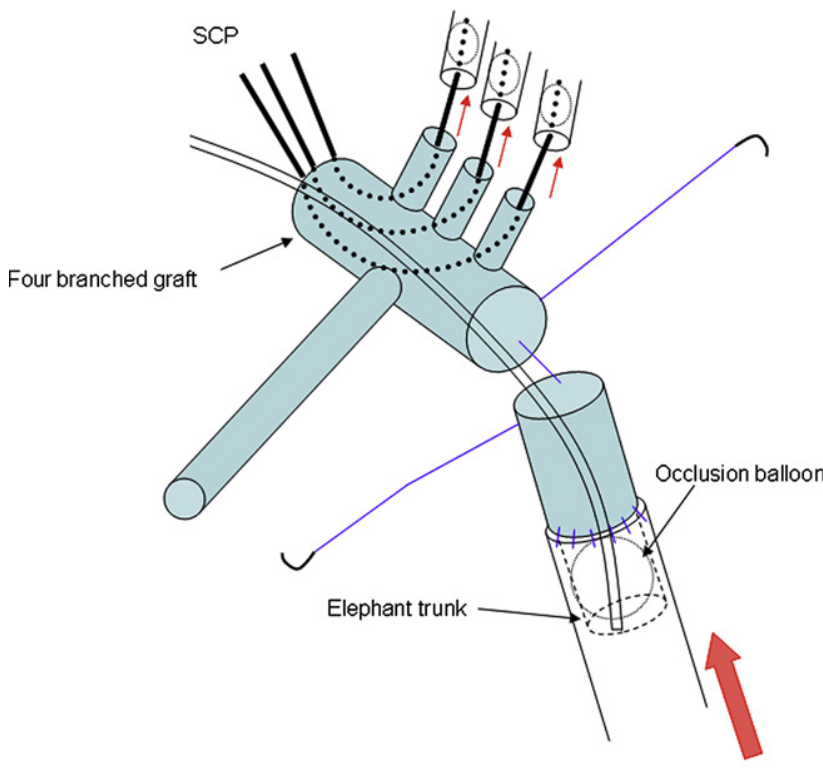

Recirculation from femoral artery

FIGURE 1. Separate lower-body perfusion. After the distal anastomosis, lower-body perfusion is resumed through a cannula placed in the femoral artery with balloon occlusion of the elephant trunk, and a 4-branched vascular graft is anastomosed to the elephant trunk graft. $S C P$, Selective cerebral perfusion. 


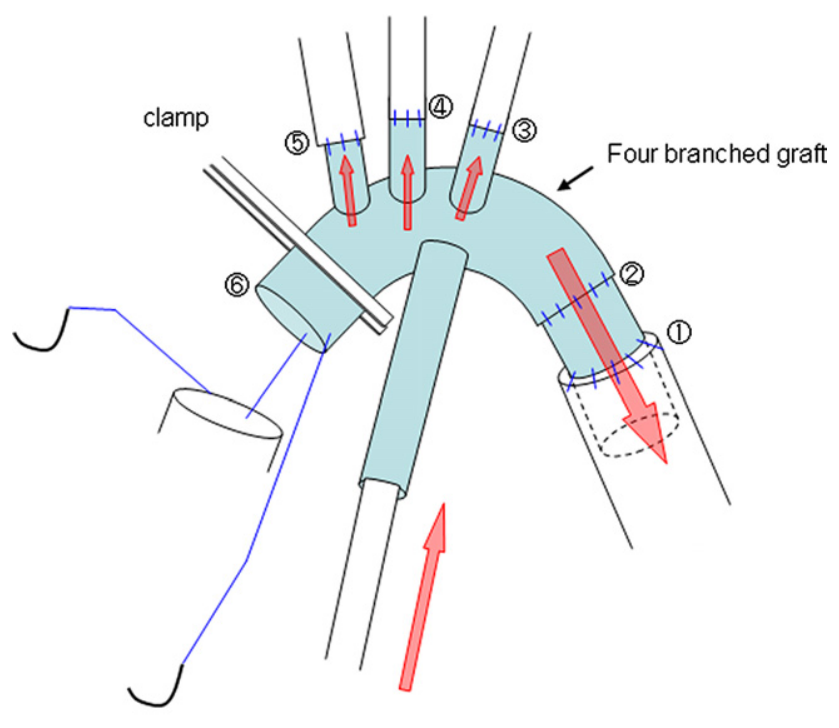

Recirculation through the $4^{\text {th }}$ branch

FIGURE 2. Sequence of anastomotic procedures. The circled numbers show the order of anastomoses. The proximal aortic anastomosis is done at the end during rewarming.

operative deaths included sepsis due to deep sternal wound infection $(\mathrm{n}=1)$, stroke $(\mathrm{n}=1)$, rupture of residual dissection $(\mathrm{n}=1)$, and ischemic bowel necrosis $(\mathrm{n}=1)$. Permanent neurologic deficit newly developed in 5 patients $(4.2 \%), 3$ patients $(2.5 \%)$ had transient neurologic deficit, and 2 patients $(1.7 \%)$ had paraparesis. Nine patients $(7.6 \%)$ had new postoperative renal insufficiency, 5 patients $(4.2 \%)$ required new temporary dialysis, and no patient required new chronic dialysis. The other postoperative complications are shown in Table 2. Compared with our previous series, the incidences of renal insufficiency and respiratory failure were significantly lower, and the operative mortality was lower $(3.4 \%$ vs $10.4 \%)$, although the difference was not statistically significant. The amount of red cell transfusion was significantly reduced (Table 2). KaplanMeier analysis showed that actuarial 4-year survival was $86.5 \% \pm 3.3 \%$ (Figure 3 ).

\section{DISCUSSION}

In this recent series of TAR, the operative mortality was $3.4 \%$ for all patients, $1.6 \%$ for elective cases, and $5.4 \%$ for emergency cases. These mortalities are at the lowest level among those previously reported, despite a high rate of emergency cases $(47 \%)$. Recent studies have reported operative mortalities of TAR ranging from $2 \%$ to $12 \%$ (some studies showed 30-day or in-hospital mortality instead of operative mortality). ${ }^{3-8}$ The rates of emergency cases in those studies range from $0 \%$ to $39 \%$.

We introduced the combination of a stepwise distal anastomosis technique, moderate $\mathrm{HCA}\left(25^{\circ} \mathrm{C}\right), \mathrm{SCP}$, and
TABLE 2. Operative variables and outcomes

\begin{tabular}{lccc}
\hline & $\begin{array}{c}\text { Current } \\
\text { technique } \\
(\mathbf{n = 1 1 9 )}\end{array}$ & $\begin{array}{c}\text { Arch first } \\
\text { technique } \\
(\mathbf{n}=\mathbf{6 7})\end{array}$ & $\begin{array}{c}\boldsymbol{P} \\
\text { value }\end{array}$ \\
\hline Operation time (min) & $313 \pm 67$ & $362 \pm 92$ & $<.001$ \\
Cardiopulmonary bypass times (min) & $183 \pm 41$ & $213 \pm 55$ & $<.001$ \\
Lower-body HCA time (min) & $47 \pm 15$ & $69 \pm 26$ & $<.001$ \\
Length of elephant trunk graft (cm) & $5.0 \pm 0.8$ & $4.5 \pm 1.0$ & .003 \\
Operative mortality & $4(3.4 \%)$ & $7(10.4 \%)$ & .053 \\
Permanent neurologic deficit & $5(4.2 \%)$ & $5(7.5 \%)$ & .271 \\
Transient neurologic deficit & $3(2.5 \%)$ & $3(4.5 \%)$ & .365 \\
Paraparesis & $2(1.7 \%)$ & $2(3.0 \%)$ & .459 \\
Renal insufficiency & $9(7.6 \%)$ & $18(26.9 \%)$ & $<.001$ \\
Temporary hemodialysis & $5(4.2 \%)$ & $6(9.0 \%)$ & .160 \\
Chronic dialysis & $0(0 \%)$ & $0(0 \%)$ & N/A \\
Respiratory failure & $15(12.6 \%)$ & $22(32.8 \%)$ & .001 \\
Reexploration for breeding & $4(3.4 \%)$ & $2(3.0 \%)$ & .627 \\
Median amount of red cell & 1680 & 2660 & $<.001$ \\
$\quad$ transfusion (mL) & & & \\
\hline
\end{tabular}

N/A, Not applicable.

separate lower-body perfusion in August 2006. Subsequently, we have successfully decreased operation, cardiopulmonary bypass, and circulatory arrest times. The operative mortality has been reduced from $10.4 \%$ to $3.4 \%$.

Our stepwise distal anastomosis technique enables the elephant trunk graft to be sewn to the distal aorta with open running sutures and the hemostasis to be confirmed. It is rare that we need to put additional sutures on the distal anastomosis after the first confirmation of hemostasis. The potential drawback of this technique is a prolonged HCA time because of additional graft-to-graft anastomoses. ${ }^{1} \mathrm{~A}$ prolonged HCA time may induce organ ischemia, coagulopathy, and endothelial dysfunction, ${ }^{2,9}$ and has been shown to be a predictor of late mortality. ${ }^{10}$

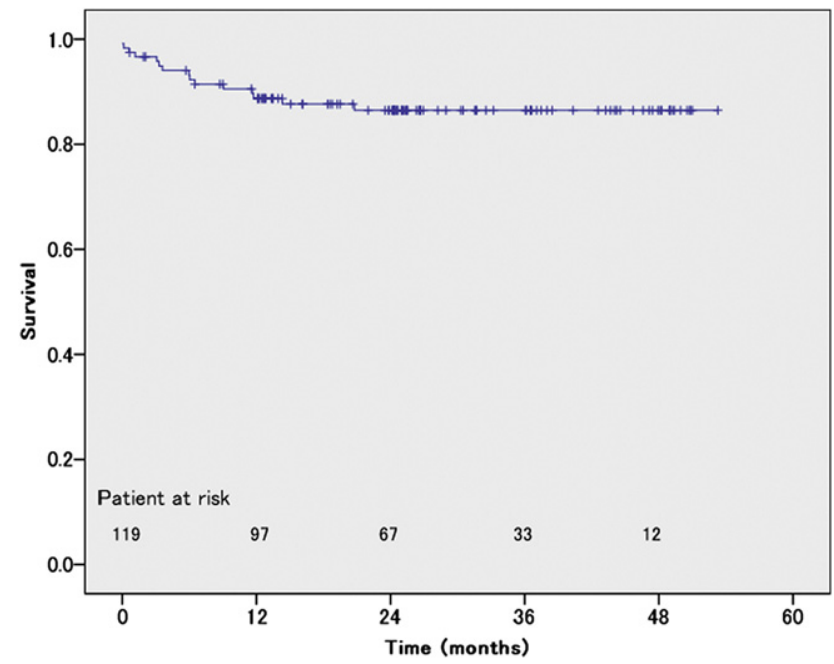

FIGURE 3. Kaplan-Meier survival curve of 119 patients undergoing TAR. 
With our technique, this potential drawback was avoided by resuming lower-body perfusion as soon as the distal anastomosis was finished. We prefer using balloon occlusion to clamping the graft during lower-body perfusion. Balloon occlusion does not deform the graft, which enables an easy anastomosis in the deep chest. In some cases, there is no room for clamping between the distal anastomosis and the graft-to-graft anastomosis.

Our perfusion strategy was designed to minimize HCA time and ischemic time of all organs. The cerebral HCA time is the time required to insert 3 balloon catheters into the cerebral branches, which takes only a few minutes. The mean body HCA time was $47 \pm 15$ minutes in the recent series. The previously reported body HCA times range from 60 to 78 minutes using the stepwise distal anastomosis technique. ${ }^{3,5,7}$ With these short cerebral and body HCA times, a deep $\mathrm{HCA}\left(15^{\circ} \mathrm{C}-20^{\circ} \mathrm{C}\right)$ is not required.

The advantages of SCP have been shown. ${ }^{11,12}$ Moderate HCA in combination with SCP has been shown as safe and effective in terms of cerebral protection. ${ }^{13,14}$ Several types of SCP have been presented. ${ }^{4,13-16}$ We perfuse all of 3 cerebral branches separately by using balloon catheters. This method provides quick establishment of whole cerebral perfusion regardless of the cerebral arterial anatomy. The trifurcated graft technique requires a long cerebral HCA time. ${ }^{4}$ The axillary arterial cannulation is a useful technique $^{16}$; however, it is not feasible in emergency salvage situations or cases with an aberrant right subclavian artery. In our series, the incidences of permanent neurologic deficit were $4.2 \%$ in all patients, $3.2 \%$ in patients undergoing elective surgery, and $5.4 \%$ in patients undergoing emergency surgery. These results are comparable to those previously reported $(3.2 \%-9 \%))^{3,4,6,7,14}$ In our previous series, the incidence of permanent neurologic deficit was higher, although the difference was not statistically significant.

The separate lower-body perfusion reduces the ischemic time of the spine, kidney, visceral organs, and legs. In our recent series, 2 patients $(1.7 \%)$ had paraparesis, probably due to perioperative spinal ischemia. The incidence of paraparesis was lower compared with that in our previous series, although the difference was not statistically significant. Two patients had a long $(8-\mathrm{cm})$ elephant trunk graft. We think that a long elephant trunk graft may have interfered with spinal perfusion. The average length of the elephant trunk graft was longer in the recent series compared with the previous series. However, we stopped using an elephant trunk graft more than $5 \mathrm{~cm}$ in length because we observed 2 cases of paraparesis in the recent series. Few studies have described the incidence of paraplegia/paraparesis after TAR. Two different studies have reported that paraplegia/ paraparesis occurred in about $4 \%$ of patients undergoing TAR. ${ }^{3,17}$

Renal insufficiency after HCA is common, although the incidence varies depending on the definition. ${ }^{18}$ In our recent series, the incidences of postoperative renal insufficiency, temporary dialysis, and chronic dialysis were $7.6 \%$, $4.2 \%$, and $0 \%$, respectively. The incidence of renal insufficiency was significantly lower than that in our previous series. Previous studies have reported the incidence of renal insufficiency requiring dialysis after TAR ranges from $3.7 \%$ to $5 \%{ }^{3,4}$

The separate lower-body perfusion technique allows us to start rewarming the patient earlier. We apply a stepwise rewarming method as described above, which saves cardiopulmonary and operation times.

\section{Study Limitations}

There are limitations of observational nature. A randomized prospective study may be ideal to assess the effectiveness of our perfusion strategy without bias.

\section{CONCLUSIONS}

TAR, using our stepwise distal anastomosis technique and modified perfusion strategy, provides a simple distal aortic anastomosis and secure hemostasis, minimizes organ ischemic time, and has demonstrated excellent operative outcomes.

\section{References}

1. Ogino H, Ando M, Sasaki H, Minatoya K. Total arch replacement using stepwise distal anastomosis for arch aneurysm with distal extension. Eur J Cardiothorac Surg. 2006;29:255-7.

2. Sasaki M, Usui A, Yoshikawa M, Akita T, Ueda Y. Arch-first technique performed under hypothermic circulatory arrest with retrograde cerebral perfusion improves neurological outcomes for total arch replacement. Eur J Cardiothorac Surg. 2005;27:821-5.

3. Ueda T, Shimizu H, Hashizume K, Koizumi K, Mori M, Shin H, et al. Mortality and morbidity after total arch replacement using branched arch graft with selective antegrade cerebral perfusion. Ann Thorac Surg. 2003;76:1951-6.

4. Spielvogel D, Halstead JC, Meier M, Kadir I, Lansman SL, Shahani R, et al. Aortic arch replacement using a trifurcated graft: simple, versatile, and safe. Ann Thorac Surg. 2005;80:90-5.

5. Sasaki H, Ogino H, Matsuda H, Minatoya K, Ando M, Kitamura S. Integrated total arch replacement using selective cerebral perfusion: a 6-year experience. Ann Thorac Surg. 2007;83:S805-10.

6. Kazui T, Yamashita K, Washiyama N, Terada H, Bashar AH, Suzuki K, et al. Aortic arch replacement using selective cerebral perfusion. Ann Thorac Surg. 2007;83:S796-8.

7. Minakawa M, Fukuda I, Yamauchi S, Watanabe K, Kawamura T, Taniguchi S, et al. Early and long-term outcome of total arch replacement using selective cerebral perfusion. Ann Thorac Surg. 2010;90:72-7.

8. Ergin MA, Galla JD, Lansman SL, Quintana C, Bodian C, Griepp RB. Hypothermic circulatory arrest in operations on the thoracic aorta. Determination of operative mortality and neurologic outcome. J Thorac Cardiovasc Surg. 1994;107:788-97.

9. Cooper WA, Duarte IG, Thourani VH, Nakamura S, Wang NP, Brown WM, et al. Hypothermic circulatory arrest causes multisystem vascular endothelial dysfunction and apoptosis. Ann Thorac Surg. 2000;69:696-702.

10. Patel HJ, Nguyen C, Diener AC, Passow MC, Salata D, Deeb GM. Open arch reconstruction in the endovascular era: analysis of 721 patients over 17 years. J Thorac Cardiovasc Surg. 2011;141:1417-23.

11. HaglC, Ergin MA, Galla JD, Lansman SL, McCullough JN, Spielvogel D, et al. Neurologic outcome after ascending aorta-aortic arch operations: effect of brain protection technique in high-risk patients. J Thorac Cardiovasc Surg. 2001;121:1107-21.

12. Harrington DK, Walker AS, Kaukuntla H, Bracewell RM, Clutton-Brok TH, Faroqui M, et al. Selective antegrade cerebral perfusion attenuates brain metabolic deficit in aortic arch surgery. A prospective randomized trial. Circulation. 2004;110(Suppl II):II-231-6. 
13. Khaladj N, Shrestha M, Meck S, Peterss S, Kamiya H, Kallenbach K, et al. Hypothermic circulatory arrest with selective antegrade cerebral perfusion in ascending aortic and aortic arch surgery: a risk factor analysis for adverse outcome in 501 patients. J Thorac Cardiovasc Surg. 2008;135:908-14.

14. Leshnower BG, Myung RJ, Kilgo PD, Vassiliades TA, Vega JD, Thourani VH, et al. Moderate hypothermia and unilateral selective antegrade cerebral perfusion: a contemporary cerebral protection strategy for aortic arch surgery. Ann Thorac Surg. 2010;90:547-54

15. Kazui T, Washiyama N, Muhammad BA, Terada H, Yamashita K, Takinami M. Improved result of atherosclerotic arch aneurysm operations with a refined technique. J Thorac Cardiovasc Surg. 2001;121:491-9.
16. Ogino H, Sasaki H, Minatoya K, Matsuda H, Tanaka H, Watanuki H, et al. Evolving arch surgery using integrated antegrade selective cerebral perfusion: impact of axillary artery perfusion. J Thorac Cardiovasc Surg. 2008;136: 641-9.

17. Taniguchi K, Toda K, Hata H, Shudo Y, Matsue H, Takahashi T, et al. Elephant trunk anastomosis proximal to origin of innominate artery in total arch replacement. Ann Thorac Surg. 2007;84:1729-34.

18. Augoustides JG, Pochettino A, Ochroch EA, Cowie D, Weiner J, Gambone AJ, et al. Renal dysfunction after thoracic aortic surgery requiring deep hypothermic circulatory arrest: definition, incidence, and clinical predictors. J Cardiothorac Vasc Anesth. 2006;20:673-7. 